\title{
Risk factors for surgical site infection following nonshunt pediatric neurosurgery: a review of 9296 procedures from a national database and comparison with a single-center experience
}

\author{
Brandon A. Sherrod, BS, Anastasia A. Arynchyna, MPH, James M. Johnston, MD, \\ Curtis J. Rozzelle, MD, Jeffrey P. Blount, MD, W. Jerry Oakes, MD, and \\ Brandon G. Rocque, MD, MS \\ Department of Neurosurgery, Division of Pediatric Neurosurgery, The University of Alabama at Birmingham and Children's \\ Hospital of Alabama, Birmingham, Alabama
}

\begin{abstract}
OBJECTIVE Surgical site infection (SSI) following CSF shunt operations has been well studied, yet risk factors for nonshunt pediatric neurosurgery are less well understood. The purpose of this study was to determine SSI rates and risk factors following nonshunt pediatric neurosurgery using a nationwide patient cohort and an institutional data set specifically for better understanding SSI.

METHODS The authors reviewed the American College of Surgeons National Surgical Quality Improvement Program-Pediatric (ACS NSQIP-P) database for the years 2012-2014, including all neurosurgical procedures performed on pediatric patients except CSF shunts and hematoma evacuations. SSI included deep (intracranial abscesses, meningitis, osteomyelitis, and ventriculitis) and superficial wound infections. The authors performed univariate analyses of SSI association with procedure, demographic, comorbidity, operative, and hospital variables, with subsequent multivariate logistic regression analysis to determine independent risk factors for SSI within 30 days of the index procedure. A similar analysis was performed using a detailed institutional infection database from Children's of Alabama (COA).

RESULTS A total of 9296 nonshunt procedures were identified in NSQIP-P with an overall 30 -day SSI rate of $2.7 \%$. The 30 -day SSI rate in the COA institutional database was similar (3.3\% of 1103 procedures, $p=0.325)$. Postoperative time to SSI in NSQIP-P and COA was $14.6 \pm 6.8$ days and $14.8 \pm 7.3$ days, respectively (mean \pm SD). Myelomeningocele (4.3\% in NSQIP-P, $6.3 \%$ in COA), spine (3.5\%, 4.9\%), and epilepsy (3.4\%, 3.1\%) procedure categories had the highest SSI rates by procedure category in both NSQIP-P and COA. Independent SSI risk factors in NSQIP-P included postoperative pneumonia (OR 4.761, 95\% Cl 1.269-17.857, $p=0.021$ ), immune disease/immunosuppressant use (OR 3.671, $95 \% \mathrm{Cl} 1.371-9.827, p=0.010)$, cerebral palsy $(\mathrm{OR} 2.835,95 \% \mathrm{Cl} 1.463-5.494, \mathrm{p}=0.002)$, emergency operation (OR $1.843,95 \% \mathrm{Cl} 1.011-3.360, \mathrm{p}=0.046)$, spine procedures (OR 1.673, 95\% Cl 1.036-2.702, $\mathrm{p}=0.035)$, acquired CNS abnormality (OR 1.620, 95\% Cl 1.085-2.420, $p=0.018)$, and female sex (OR 1.475, 95\% Cl 1.062-2.049, $p=0.021)$. The only COA factor independently associated with SSI in the COA database included clean-contaminated wound classification (OR 3.887, 95\% Cl 1.354-11.153, $p=0.012$ ), with public insurance (OR 1.966, 95\% Cl 0.957-4.041, p = 0.066) and spine procedures (OR 1.982, 95\% $\mathrm{Cl} 0.955-4.114, \mathrm{p}=0.066)$ approaching significance. Both NSQIP-P and COA multivariate model C-statistics were $>0.7$.
\end{abstract}

CONCLUSIONS The NSQIP-P SSI rates, but not risk factors, were similar to data from a single center. https://thejns.org/doi/abs/10.3171/2016.11.PEDS16454

KEY WORDS surgical site infection; NSQIP; complication; pediatric neurosurgery

ABBREVIATIONS ACS = American College of Surgeons; $\mathrm{AUC}=$ area under the curve; $\mathrm{COA}=$ Children's of Alabama; $\mathrm{CPT}=$ Current Procedural Terminology; $\mathrm{MMC}=$ myelomeningocele; NSQIP = National Surgical Quality Improvement Program; NSQIP-P = NSQIP-Pediatric; ROC = receiver operating characteristic; SSI = surgical site infection.

SUBMITTED August 8, 2016. ACCEPTED November 9, 2016

INCLUDE WHEN CITING Published online February 10, 2017; DOI: 10.3171/2016.11.PEDS16454. 
$\mathrm{S}$ URGICAL site infection (SSI) is a relatively common complication of surgery with significant associated morbidity, mortality, and cost. ${ }^{7,18,31}$ SSI rates have declined dramatically since the early days of surgery due to ubiquitous use of sterile technique, antibiotic prophylaxis, and improved postoperative wound care. ${ }^{32}$ Despite these advances, SSI is still occasionally encountered after surgery. Some SSIs have been classified as "never events" after select procedures and are, to some extent, considered preventable. ${ }^{25,32}$ Furthermore, SSI can lead to serious complications including sepsis or death, highlighting the need to prevent SSI where possible.

Numerous studies have investigated postoperative infection after pediatric and adult neurosurgery, with varied rates of infection by procedure type. $1,7,13,14,20,21,24,25,27$, 28,33-35,37,40,41,43-45,50,52 Pediatric neurosurgical patients are at the greatest risk of SSI relative to all other pediatric surgical patients, particularly patients with CSF shunts..$^{11,16,17}$ Therefore, substantial efforts toward study and prevention of shunt infection have been a top priority of pediatric neurosurgeons. Study of nonshunt neurosurgical SSI in pediatric patients has not been as thorough. Although multiple studies have suggested techniques for lowering SSI risk in neurosurgery, including double-gloving, antibiotic prophylaxis, and laminar airflow circulation,,$^{1,7-9}$, $14,33,34,36,40,47$ there remains ample opportunity to study and implement additional measures to further reduce SSI risk, particularly in nonshunt surgery.

Data on national rates of SSI following nonshunt procedures are lacking. Most studies on SSI after pediatric neurosurgical procedures are single-center studies focused on one type of procedure. Therefore, a nationwide, validated clinical database with prospectively collected patient data could be useful for identifying national SSI rates and risk factors across different procedures. The American College of Surgeons National Surgical Quality Improvement Program (ACS NSQIP) database contains clinical patient information, prospectively collected by trained data $a b-$ stractors with a minimum $80 \%$ required follow-up at 30 days, providing high-quality data for such an analysis. ${ }^{11}$ One limitation of this database is a dearth of neurosurgery-specific variables and variables that might be collected when specifically studying SSI. These provide essential risk factor and procedure information. Therefore, the reliability and applicability of NSQIP neurosurgical data has been challenged. ${ }^{10} \mathrm{~A}$ comparison of NSQIP to a neurosurgery-specific patient database, constructed with a focus on SSI, represents an opportunity to evaluate the applicability of NSQIP within neurosurgery. ${ }^{22}$

The goal of the current study is to identify risk factors for SSI in nonshunt pediatric neurosurgery. In addition, we will compare SSI data from the NSQIP database to a neurosurgery-specific patient database maintained at our own institution. In this way, we can determine whether the variables that are associated with SSI in NSQIP are also associated with SSI in the more specific and more detailed institutional database. We can also determine whether there are additional variables from the institutional database that are important risk factors for infection but are not included in the NSQIP data.

\section{Methods}

\section{Data Source and Reliability}

The ACS NSQIP-Pediatric (NSQIP-P) is a clinical patient database with 50 children's hospitals participating in year 2012, 56 hospitals participating in year 2013, and 64 hospitals in year 2014..$^{3-5}$ This database is maintained and supported by general pediatric surgery services. Cases involving patients aged 18 years or older at the time of the index procedure, trauma, and transplantation are excluded from the NSQIP-P data set. Each NSQIP site has an ACS-trained and -certified data abstractor. Interrater disagreement rates are approximately $2 \%$ according to an ACS audit, well below the 5\% disagreement rate considered "acceptable" by the ACS. ${ }^{3-5}$

Previous studies have shown that NSQIP-P is a highly reliable clinical data set, with $91.4 \%$ confirmed follow-up at 30 days. ${ }^{11}$ The data set does not capture any events after 30 postoperative days. Studies investigating NSQIP-P for data reliability have found that completeness of data collection for all variables was greater than $95 \%$ with $98 \%$ interrater reliability in the early stages of program implementation. ${ }^{38}$ Compared with administrative data sets such as the National (Nationwide) Inpatient Sample (NIS) that rely heavily on ICD-9 coding for accuracy, the NSQIP data set is demonstrably more sensitive and specific for clinical surgical data such as morbidity and mortality. ${ }^{51}$ NSQIP-P data are more sensitive for SSI capture than billing claims and nosocomial infection marker data. ${ }^{20}$

The Children's of Alabama (COA) pediatric neurosurgery infection database was constructed by retrospective medical record review for the purpose of determining risk factors for SSI. Pediatric neurosurgical procedures from January 2009 through March 2012 at COA were included in the original data set. COA is a large-volume, tertiary care hospital serving a multistate area in the southeastern United States. Data on both 30-day and 90-day SSI were collected, with minimum follow-up of 90 days for all patients.

\section{Data Acquisition and Variables of Interest}

The authors queried the 2012, 2013, and 2014 ACS NSQIP-P participant use file for patients treated by a neurosurgeon (Fig. 1). Procedure categorization was conducted using previously described methods ${ }^{42}$ Briefly, after filtering by surgical subspecialty, procedures were categorized by Current Procedural Terminology (CPT) code into the following categories: spine, craniotomy for neoplasm, Chiari decompression, craniosynostosis/craniofacial, myelomeningocele (MMC) closure, epilepsy, skin lesion, and other (baclofen pump placement or removal representing more than $80 \%$ of this category). Figure 1 displays the CPT codes included within each category. Epilepsy procedures were not recorded in the NSQIP-P data set until 2014. Cerebrospinal fluid shunting procedures have a higher risk of infection and have been the focus of previous, detailed work. It is also difficult to capture known risk factors for CSF shunt infection in an administrative database. ${ }^{43}$ Therefore, shunt/ventricular catheter procedures were excluded from the analysis. Trauma cases (e.g., hematoma evacuation) are not included in the NSQIP-P 


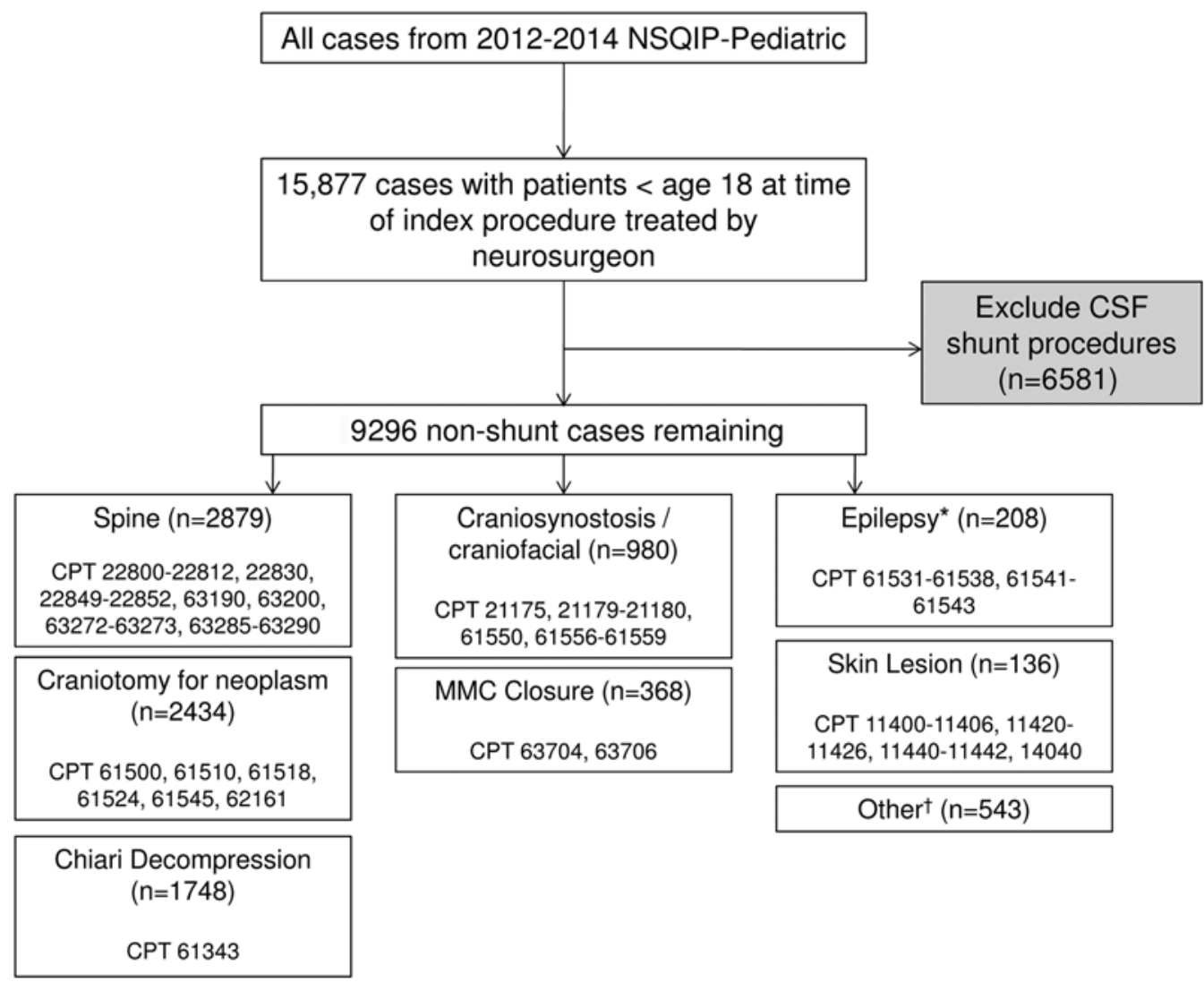

FIG. 1. Cohort selection from the 2012-2014 NSQIP-P data set. Trauma cases (e.g., hematoma evacuations) are excluded automatically from all NSQIP-P data capture. *Epilepsy procedures were not included in the 2012-2013 data set. †"Other" procedures are primarily baclofen pump placement or replacement $(>80 \%)$.

data set. A similar procedure categorization and case exclusion method was used for data from COA.

Patient demographic variables in NSQIP-P included age, sex, year of operation, race, gestational age at birth, and neonate status. NSQIP-P does not contain socioeconomic data such as insurance class; however, insurance data were analyzed from the COA data set. Variables describing patient comorbidities, hospital stay details, and operative details variables in NSQIP-P are provided in Supplemental Table S1.

COA hospital and operative variables included total length of stay, time from operation to discharge, time from admission to operation, prior operation within 30 days, length of operation, perioperative blood transfusion, wound classification, surgeon, prophylactic antibiotic use, implant use, number of operating room personnel, and calendar quarter of operation.

Surgical site infection is coded in NSQIP-P as 3 different subtypes according to CDC definitions: superficial incisional SSI, deep incisional SSI, and organ/space SSI. ${ }^{26}$ These 3 subtypes were combined into 1 primary outcome, any SSI, because the COA data did not distinguish between deep or superficial SSI. The COA data set was collected specifically for neurosurgical infection outcomes research, with more attention paid to infectious organism and site of culture than level of wound infection. Therefore, to compare COA and NSQIP SSI outcomes, we analyzed the single outcome of any SSI. SSI is coded in
NSQIP-P if at least one of the following is true: the superficial wound/deep wound/operative organ/operative space area has purulent drainage; an abscess of the deep wound/ organ space is found by radiographic imaging modalities, physical examination of the surgical wound, reoperation for wound exploration or debridement, or by histopathological modalities; organisms are isolated from an aseptically obtained wound culture; greater than or equal to one of the signs or symptoms of SSI are present (fever $>38^{\circ} \mathrm{C}$, wound dehiscence, pain/tenderness, or localized swelling, erythema, or heat; not a valid criterion if wound cultures are negative); or SSI diagnosis by an attending physician or surgeon. Organ/space SSIs relevant to neurosurgery that are explicitly mentioned in NSQIP-P infection criteria include osteomyelitis, intracranial abscesses, dural abscesses, meningitis, ventriculitis, and spinal abscesses. In the COA infection database, infection with documented positive cultures from CSF, blood, wound, abscess, or implant was required for SSI coding. Results of Gram stain alone were not sufficient for SSI coding in NSQIP-P or COA.

Data on days to diagnosis of SSI were also analyzed. In the NSQIP-P data, time to SSI was captured as time to first positive SSI criterion (see above). In the COA data, time to SSI was captured as time to collection of the first positive culture from the appropriate site (wound, CSF, blood, abscess, or implant). NSQIP-P is limited to 30-day postoperative follow-up; data on 30-day SSI were collected. Data on both 30-day and 90-day SSI were collected for COA. 


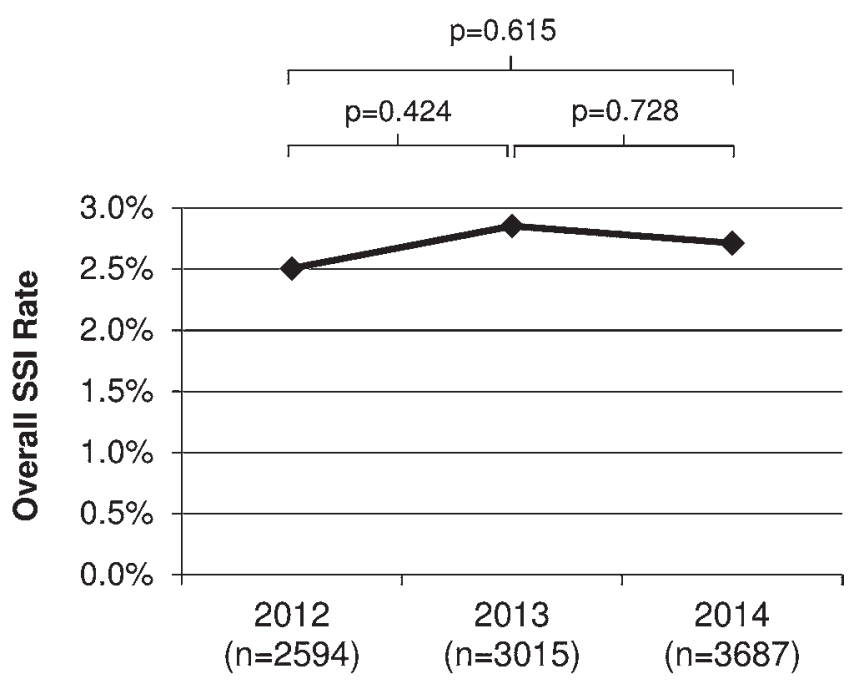

FIG. 2. SSI trend over time in NSQIP-P. Statistical analysis was performed via binary logistic regression.

\section{Statistical Analysis}

The association of predictor variables with any postoperative 30-day SSI occurrence was investigated via univariate analysis. This initial unadjusted analysis was performed using a chi-square test, an independent-samples t-test, and binary logistic regression where appropriate. Contingency tables were created for all categorical variables to calculate relative frequencies of SSI outcome with corresponding unadjusted odds ratios and $95 \%$ confidence intervals. Variables reaching an alpha value of 0.2 or less in the univariate analysis were then entered into a multivariate adjusted binary logistic regression analysis to determine independent risk factors for SSI. Variables were considered independently significant at $p<0.05$. Receiver operating characteristic (ROC) curve analysis was performed with calculation of area under the curve (AUC), or the C-statistic, for the multivariate logistic regression analysis. Statistical analysis was performed using SPSS version 23.0 (IBM Corporation).
The institutional review board (IRB) of our institution does not require IRB approval for research using the NSQIP-P data set because NSQIP data are deidentified and HIPAA (Health Insurance Portability and Accountability Act) compliant. ${ }^{48}$ Furthermore, for additional patient privacy protection, facility identifiers are not included in the NSQIP-P data set. IRB approval was granted, however, for construction, maintenance, and analysis of the COA neurosurgical infection database in compliance with research protocols at the University of Alabama at Birmingham.

\section{Results}

\section{Overall SSI and Procedural Frequencies}

A total of 9296 nonshunt neurosurgical procedures performed on pediatric patients from 2012 through 2014 were identified in NSQIP-P. A total of 2594 nonshunt neurosurgical procedures from 50 participating children's hospitals were identified in 2012, 3015 procedures from 56 children's hospitals in 2013, and 3687 procedures from 64 children's hospitals in 2014. The overall 30-day SSI rate was $2.7 \%(\mathrm{n}=251)$. There was no significant difference between rates of SSI per year during the 2012-2014 period (Fig. 2). SSI occurred $14.6 \pm 6.8$ days postoperatively (mean $\pm \mathrm{SD}$ ). The time to 30-day SSI in the NSQIP-P cohort is shown in Fig. 3A.

A total of 1103 nonshunt procedures performed by pediatric neurosurgeons from January 2009 through March 2012 were identified in the COA institutional data. The overall 30-day SSI rate was 3.3\% $(\mathrm{n}=36, \mathrm{p}=0.325$ vs NSQIP-P 30-day SSI rate). The overall 90-day SSI rate was $3.9 \%$. SSI occurred $14.8 \pm 7.3$ days (mean \pm SD) postoperatively for the 30-day infection group, whereas it occurred $20.6 \pm 16.5$ days postoperatively in the 90-day infection group. Data on time to 30-day and 90-day SSI are displayed in Fig. 3B and C, respectively. Fifty percent of 30-day COA SSIs were initially cultured from the wound, $36 \%$ were cultured from CSF, $6 \%$ were cultured from blood, and the remaining positive cultures were from ab-
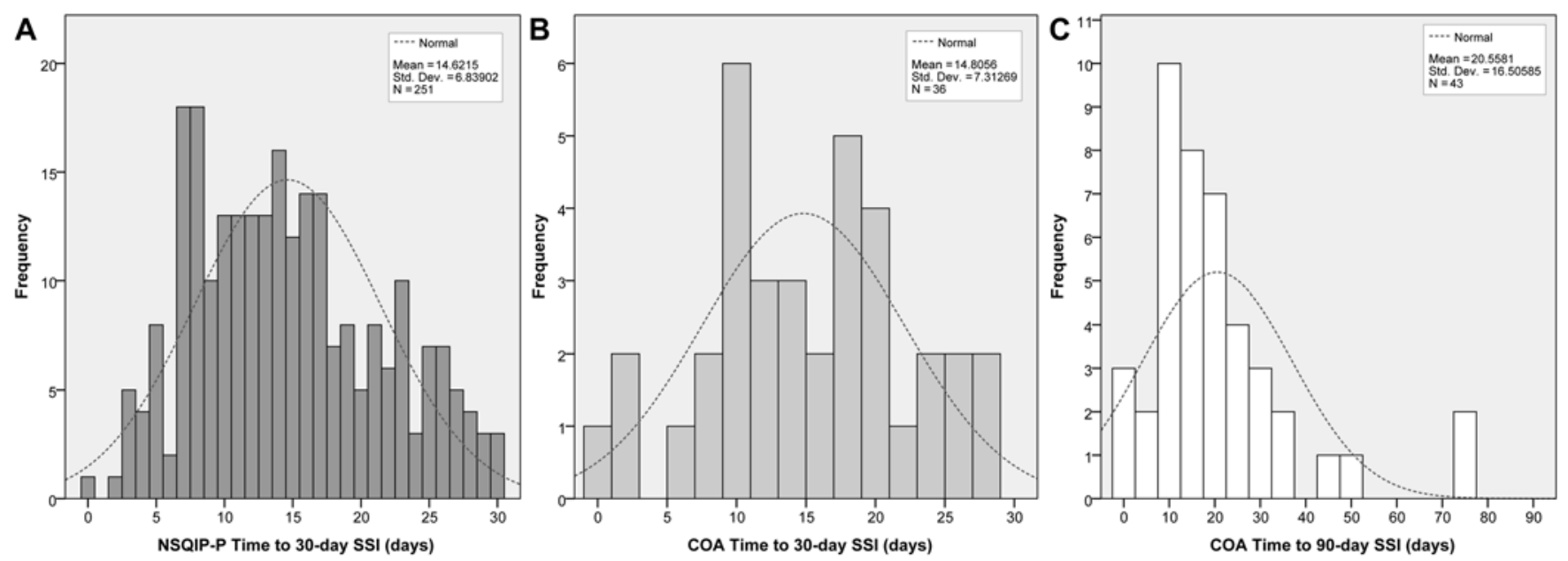

FIG. 3. Time to SSI event histograms with expected normal distribution curves shown in dashed lines. A: NSQIP 30-day time to SSI. Skewness statistic 0.359, standard error 0.154. B: COA 30-day time to SSI. Skewness statistic -0.073 , standard error 0.393. C: COA 90-day time to SSI. Skewness statistic 2.035, standard error 0.361 . Std. Dev. = standard deviation. 
TABLE 1. Thirty-day SSI rates by general procedure category (unadjusted univariate analysis)

\begin{tabular}{|c|c|c|c|c|c|c|c|c|}
\hline \multirow[b]{2}{*}{ Procedure Category } & \multicolumn{4}{|c|}{ NSQIP-P } & \multicolumn{4}{|c|}{$\mathrm{COA}$} \\
\hline & $\begin{array}{c}\text { No. of } \\
\text { Procedures } \\
\text { (\% of total) }\end{array}$ & $\begin{array}{c}\text { No. of } \\
\text { SSIs (\%) }\end{array}$ & $\begin{array}{c}\text { OR } \\
(95 \% \mathrm{Cl})\end{array}$ & $\begin{array}{c}p \\
\text { Value }\end{array}$ & $\begin{array}{l}\text { No. of } \\
\text { Procedures } \\
\text { (\% of total) }\end{array}$ & $\begin{array}{c}\text { No. of } \\
\text { SSIs (\%) }\end{array}$ & $\begin{array}{c}\text { OR } \\
(95 \% \mathrm{Cl})\end{array}$ & $\begin{array}{c}p \\
\text { Value }\end{array}$ \\
\hline Spine & $2879(31)$ & $101(3.5)$ & $1.519(1.176-1.963)$ & 0.002 & $283(26)$ & $14(4.9)$ & $1.888(0.952-3.742)$ & 0.079 \\
\hline Craniotomy for neoplasm & $2434(26)$ & $60(2.5)$ & $0.883(0.658-1.184)$ & 0.424 & $165(15)$ & $5(3.0)$ & $0.914(0.350-2.386)$ & 0.855 \\
\hline Chiari decompression & $1748(19)$ & $33(1.9)$ & $0.647(0.447-0.937)$ & 0.021 & $84(8)$ & $0(0)$ & NA & \\
\hline Craniosynostosis/craniofacial & $980(11)$ & $15(1.5)$ & $0.532(0.314-0.901)$ & 0.016 & $46(4)$ & $1(2.2)$ & $0.649(0.087-4.843)$ & 0.671 \\
\hline MMC closure & $368(4)$ & $16(4.3)$ & $1.681(1.002-2.821)$ & 0.068 & $48(4)$ & $3(6.3)$ & $2.065(0.610-6.987)$ & 0.203 \\
\hline Epilepsy* & $208(2)$ & $7(3.4)$ & $1.262(0.588-2.711)$ & 0.513 & $256(23)$ & $8(3.1)$ & $0.944(0.425-2.097)$ & 0.887 \\
\hline Skin lesion & $136(2)$ & $1(0.7)$ & $0.264(0.037-1.895)$ & 0.276 & $70(6)$ & $1(1.4)$ & $0.413(0.056-3.062)$ & 0.723 \\
\hline Other† & $543(6)$ & $18(3.3)$ & $1.254(0.770-2.041)$ & 0.340 & $171(14)$ & $4(2.6)$ & $0.782(0.273-2.244)$ & 0.808 \\
\hline Total & 9296 & $251(2.7)$ & & & 1103 & $36(3.3)$ & & \\
\hline
\end{tabular}

NA = not available.

Odds ratios are with respect to development of any SSI compared to all other procedures not in respective category. Statistical tests were performed using the chisquare test and Fisher exact test where appropriate. Boldface type indicates statistical significance $(p<0.05)$.

* Data on epilepsy operations were not available for 2012-2013; NSQIP only has epilepsy procedure data for 2014 . See Fig. 1 for more detailed procedural categorization by CPT code.

† The majority of procedures in "Other" category are baclofen pump placement/removal procedures (> $80 \%$ of total).

scesses or other sites. The most common infectious organism was Staphylococcus aureus.

\section{Procedural Categories}

Table 1 contains data on 30-day SSI rates by procedure category. The categories with the highest 30-day SSI rates in NSQIP-P were MMC closure (4.3\%), spine (3.5\%), and epilepsy (3.4\%). These same procedure categories were associated with the highest infection risk in data from COA $(6.3 \%, 4.9 \%$, and $3.1 \%$, respectively). Spine was the only category with a statistically significant increase in SSI risk in NSQIP-P relative to all other procedure categories $(\mathrm{p}=0.002)$, with the rate for MMC closure approaching significance $(\mathrm{p}=0.068)$. The procedure categories with the lowest 30-day SSI rates were skin lesion (0.7\%), craniosynostosis/craniofacial (1.5\%), and Chiari decompression $(1.9 \%)$-also very similar to COA data $(1.4 \%, 2.2 \%$, and $0 \%$, respectively). Craniosynostosis/craniofacial $(\mathrm{p}=$ $0.016)$ and Chiari decompression $(\mathrm{p}=0.021)$ categories were at a statistically significant decreased risk of SSI in NSQIP-P relative to all other procedure categories, while skin lesion was not. No individual procedure by CPT code had an SSI rate greater than $10 \%$.

\section{Patient Demographics and Comorbidities}

Table 2 displays results from the unadjusted univariate analysis of patient demographics associated with SSI. Younger age, neonate status, and female sex were all significant risk factors for SSI in NSQIP-P on unadjusted analysis. In the COA demographic data, no variable was significant on univariate analysis. However, younger age, public insurance status, and gestational age of 29-32 weeks were entered into the COA multivariate model $(\mathrm{p}<0.2)$.

Table 3 displays results of the unadjusted univariate analysis of patient comorbidities associated with SSI. The postoperative comorbidities shown are only reported if they occurred prior to SSI development. Multiple comor- bidities were significantly associated with SSI on unadjusted analysis, and the strongest associations were observed in patients with postoperative pneumonia, sepsis/ SIRS (systemic inflammatory response syndrome) prior to surgery, postoperative urinary tract infection, and immune disease/immunosuppressant use. No preexisting comorbidities (other than preoperative diagnoses and history of prematurity) were tracked in the COA database.

\section{Hospital and Operative Factors}

Hospital factors associated with SSI on univariate analysis are presented in Table 4. Several variables describing length of stay and discharge destination were significantly associated with SSI on unadjusted analysis in NSQIP-P. None of the hospital factors reached significance on univariate analysis for the COA data set, although length of stay (time from admission to discharge) and time from operation to discharge were entered into the COA multivariate analysis $(\mathrm{p}<0.2)$. Postoperative length of stay was only entered into multivariate models if SSI had not occurred prior to discharge.

Operative factors associated with SSI on univariate analysis are displayed in Table 5. Longer operative time, longer duration of anesthesia, emergency operation, and American Society of Anesthesiologists class were all significantly associated with SSI in NSQIP-P. The following COA operative variables were entered into the multivariate analysis $(\mathrm{p}<0.2)$ : length of operation, clean-contaminated wound class, total number of operating room personnel, and multiple circulator nurses.

\section{Multivariate Analysis}

The results of the adjusted multivariate logistic regression analysis of independent risk factors for SSI are shown in Table 6. Postoperative pneumonia, immune disease/ immunosuppressant use, cerebral palsy, emergency operation, spine procedure category, acquired CNS abnormality, 
TABLE 2. Patient demographics and unadjusted univariate 30-day SSI associations

\begin{tabular}{|c|c|c|c|c|c|c|c|c|}
\hline \multirow[b]{2}{*}{ Parameter } & \multicolumn{4}{|c|}{ NSQIP-P } & \multicolumn{4}{|c|}{$\mathrm{COA}$} \\
\hline & Overall & SSI & OR $(95 \% \mathrm{Cl})$ & $p$ Value & Overall & SSI & OR $(95 \% \mathrm{Cl})$ & $p$ Value \\
\hline Age in yrs, mean & $7.0 \pm 5.7$ & $6.1 \pm 5.6$ & $0.971^{*}(0.949-0.994)$ & 0.013 & $7.9 \pm 6.3$ & $6.4 \pm 5.5$ & $0.957^{*}(0.905-1.013)$ & 0.132 \\
\hline Neonate & $417(4.5)$ & $19(4.6)$ & $1.779(1.103-2.871)$ & 0.028 & - & - & - & - \\
\hline \multicolumn{9}{|l|}{ Sex } \\
\hline Male & $4863(52.3)$ & $115(2.4)$ & Ref & & $578(52.4)$ & $18(3.1)$ & Ref & \\
\hline Female & $4433(47.7)$ & $136(3.1)$ & 1.307 (1.016-1.681) & 0.040 & $525(47.6)$ & $18(3.4)$ & $1.105(0.569-2.146)$ & 0.769 \\
\hline \multicolumn{9}{|l|}{ Race } \\
\hline White & $7121(76.6)$ & $187(2.6)$ & Ref & & $768(69.6)$ & $23(3.0)$ & Ref & \\
\hline Black & $852(9.2)$ & $25(2.9)$ & $1.121(0.734-1.712)$ & 0.597 & $263(23.8)$ & $11(4.2)$ & $1.414(0.680-2.941)$ & 0.354 \\
\hline Asian & $220(2.4)$ & $9(4.1)$ & $1.582(0.799-3.130)$ & 0.188 & $11(1.0)$ & $0(0)$ & NA & \\
\hline Pacific Islander & $27(0.3)$ & $1(3.7)$ & $1.426(0.193-10.565)$ & 0.728 & - & - & - & - \\
\hline Native American & $46(0.5)$ & $1(2.2)$ & $0.824(0.113-6.010)$ & 0.824 & - & - & - & - \\
\hline Unknown/NA & $1030(11.1)$ & $28(2.7)$ & $1.036(0.693-1.550)$ & 0.863 & $2(0.2)$ & $0(0)$ & NA & \\
\hline Hispanic & - & - & - & - & $54(4.9)$ & $2(3.7)$ & $1.246(0.286-5.429)$ & 0.770 \\
\hline Biracial & - & - & - & - & $5(0.5)$ & $0(0)$ & NA & \\
\hline \multicolumn{9}{|l|}{ Insurance status } \\
\hline Private & - & - & - & - & $502(45.5)$ & $12(2.4)$ & Ref & \\
\hline Public & - & - & - & - & $555(50.3)$ & $24(4.3)$ & $1.857(0.919-3.753)$ & 0.085 \\
\hline Private w/ secondary public & - & - & - & - & $3(0.3)$ & $0(0)$ & NA & \\
\hline Self pay & - & - & - & - & $37(3.4)$ & $0(0)$ & NA & \\
\hline Unknown & - & - & - & - & $6(0.5)$ & $0(0)$ & NA & \\
\hline \multicolumn{9}{|l|}{ Weeks of gestation } \\
\hline$\geq 37$ & $7233(77.8)$ & $195(2.7)$ & Ref & & $848(76.9)$ & $27(3.2)$ & Ref & \\
\hline $33-36$ & $710(7.6)$ & $13(1.8)$ & $0.785(0.108-5.718)$ & 0.811 & $105(9.5)$ & $3(2.9)$ & $0.894(0.267-3.000)$ & 0.857 \\
\hline $29-32$ & $798(8.6)$ & $26(3.3)$ & $1.578(0.766-3.248)$ & 0.216 & $63(5.7)$ & $4(6.3)$ & $2.062(0.734-6.224)$ & 0.190 \\
\hline $25-28$ & $317(3.4)$ & $8(2.5)$ & $0.934(0.457-1.912)$ & 0.853 & $40(3.6)$ & $1(2.5)$ & $0.780(0.103-5.887)$ & 0.809 \\
\hline$\leq 24$ & $191(2.1)$ & $8(4.2)$ & $1.216(0.802-1.842)$ & 0.358 & $7(0.6)$ & $0(0)$ & NA & \\
\hline Unknown & $47(0.5)$ & $1(0.4)$ & $0.673(0.382-1.187)$ & 0.171 & $40(3.6)$ & $1(2.5)$ & $0.780(0.103-5.887)$ & 0.809 \\
\hline
\end{tabular}

Ref = reference.

Data are presented as number of cases (\%) unless otherwise indicated. Continuous variables are expressed as mean \pm SD. Statistical tests were performed using the Student t-test, chi-square test, and Fisher exact test where appropriate. Boldface type indicates statistical significance $(p<0.05)$.

* Per year increase.

and female sex were all independently and significantly associated with SSI in the NSQIP-P cohort. The ROC curve analysis for the NSQIP-P multivariate model yielded an AUC (C-statistic) of 0.713 (95\% CI 0.673-0.753, p < 0.001). The only independent predictor of SSI in the COA multivariate model was clean-contaminated wound class. Spine procedure category $(\mathrm{p}=0.066)$ and public insurance status $(\mathrm{p}=0.066)$ approached but did not reach the alpha value required for independent significance in the COA cohort. The ROC curve analysis for the COA multivariate model yielded an AUC of 0.701 (95\% CI 0.610-0.792, p < 0.001).

\section{Discussion}

We have identified 30-day infection rates and risk factors for SSI following nonshunt pediatric neurosurgical procedures using a national clinical database and an institutional, neurosurgery-specific database. Our results show that the nationwide NSQIP-P SSI rates are similar to those of our own institution. Spine procedures, craniotomies, and epilepsy procedures had the highest rates of SSI in both data sets. The most important findings of this study are that NSQIP-P is a reasonable tool for epidemiological data on SSI frequency, SSI is challenging to predict using the variables provided by both the NSQIP data set and a neurosurgery-specific institutional data set, and the identified risk factors in both data sets are largely not modifiable.

\section{Procedure Type and SSI}

Rates of SSI varied significantly between different procedure types, although no individual procedure had an SSI rate greater than $10 \%$. Considering categories of procedures, spine procedures were most likely to be associated with SSI. Laminectomies were at particularly high risk for SSI, comprising 3 of the top 7 procedures by SSI rate. Craniotomies for partial or subtotal hemispherectomy, excision of epileptogenic focus with electroencephalography during surgery, and excision of craniopharyngioma were also at relatively higher risk for SSI; these are typically complicated procedures with long operative times and significant underlying patient comorbidity. The relative rarity 
TABLE 3. NSQIP-P patient comorbidities and unadjusted univariate 30-day SSI associations

\begin{tabular}{|c|c|c|c|c|c|c|}
\hline Parameter & Overall & SSI & No SSI & OR & $95 \% \mathrm{Cl}$ & p Value \\
\hline \multicolumn{7}{|l|}{ Pulmonary comorbidity } \\
\hline Ventilator dependent & $220(2.4)$ & $6(2.4)$ & $214(2.4)$ & 1.011 & $0.445-2.297$ & 0.835 \\
\hline Pneumonia & $6(0.1)$ & $0(0)$ & $6(0.1)$ & 0.973 & $0.970-0.976$ & $>0.99$ \\
\hline Asthma history & $587(6.3)$ & $12(4.8)$ & $575(6.4)$ & 0.740 & $0.412-1.329$ & 0.358 \\
\hline Bronchopulmonary dysplasia/CLD & $178(1.9)$ & $8(3.2)$ & $170(1.9)$ & 1.719 & $0.836-3.533$ & 0.153 \\
\hline Oxygen support & $249(2.7)$ & $8(3.2)$ & $241(2.7)$ & 1.203 & $0.588-2.460$ & 0.551 \\
\hline Structural pulmonary abnormality & $439(4.7)$ & $18(7.2)$ & $421(4.7)$ & 1.582 & $0.970-2.581$ & 0.070 \\
\hline \multicolumn{7}{|l|}{ GI comorbidity } \\
\hline Esophageal/gastric/intestinal disease & $1149(12.4)$ & $39(15.5)$ & $1110(12.3)$ & 1.315 & $0.929-1.861$ & 0.120 \\
\hline Biliary/liver/pancreatic disease & $45(0.5)$ & $1(0.4)$ & $44(0.5)$ & 0.818 & $0.112-5.963$ & $>0.99$ \\
\hline \multicolumn{7}{|l|}{ CNS comorbidity } \\
\hline History of CVA or TBI & $476(5.1)$ & $13(5.2)$ & $463(5.1)$ & 1.012 & $0.575-1.783$ & 0.885 \\
\hline CNS tumor & $1211(13.0)$ & $38(15.1)$ & $1173(13.0)$ & 1.197 & $0.843-1.700$ & 0.297 \\
\hline Developmental delay & $2043(22.0)$ & $81(32.3)$ & $1962(21.7)$ & 1.720 & $1.314-2.252$ & $<0.001$ \\
\hline Cerebral palsy & $656(7.1)$ & $25(10.0)$ & $631(7.0)$ & 1.475 & $0.968-2.247$ & 0.079 \\
\hline Neuromuscular disorder & $849(9.1)$ & $34(13.5)$ & $815(9.0)$ & 1.582 & $1.094-2.287$ & 0.019 \\
\hline Seizure disorder & $1275(13.7)$ & $40(15.9)$ & $1235(13.7)$ & 1.199 & $0.851-1.690$ & 0.306 \\
\hline Structural/acquired CNS abnormality & $5909(63.6)$ & $188(74.9)$ & $5721(63.3)$ & 1.734 & $1.299-2.314$ & $<0.001$ \\
\hline Intraventricular hemorrhage & $187(2.0)$ & $6(2.4)$ & $181(2.0)$ & 1.199 & $0.527-2.732$ & 0.644 \\
\hline Previous cardiac surgery & $234(2.5)$ & $6(2.6)$ & $228(2.5)$ & 0.947 & $0.417-2.151$ & $>0.99$ \\
\hline Current or previous malignancy & $1468(15.8)$ & $43(17.1)$ & $1425(15.8)$ & 1.105 & $0.792-1.543$ & 0.540 \\
\hline Chemo w/in 30 days prior to surgery & $92(1.0)$ & $2(0.8)$ & $90(1.0)$ & 0.799 & $0.196-3.263$ & $>0.99$ \\
\hline RT w/in 90 days prior to surgery & $21(0.2)$ & $0(0.0)$ & $21(0.2)$ & NA & NA & $>0.99$ \\
\hline Open wound (w/ or w/o infection) & $241(2.6)$ & $11(4.4)$ & $230(2.5)$ & 1.757 & $0.947-3.260$ & 0.101 \\
\hline Tracheostomy at time of surgery & $124(1.3)$ & $5(2.0)$ & $119(1.3)$ & 1.525 & $0.618-3.764$ & 0.391 \\
\hline Immune disease or immunosuppressant use & $74(0.8)$ & $5(2.0)$ & $69(0.8)$ & 2.644 & $1.057-6.612$ & 0.049 \\
\hline Steroid use & $792(8.5)$ & $29(11.6)$ & $763(8.4)$ & 1.418 & $0.956-2.103$ & 0.085 \\
\hline Nutritional support (IV or NG tube) & $608(6.5)$ & $27(10.8)$ & $581(6.4)$ & 1.756 & $1.168-2.641$ & 0.009 \\
\hline Congenital malformation, any system & $3533(38.0)$ & $108(43.0)$ & $3425(37.9)$ & 1.239 & $0.962-1.597$ & 0.100 \\
\hline SIRS/sepsis w/in 48 hrs before surgery & $45(0.5)$ & $4(1.6)$ & $41(0.5)$ & 3.556 & $1.264-10.006$ & 0.033 \\
\hline Postop urinary tract infection* & $102(1.1)$ & $7(2.8)$ & $95(1.1)$ & 2.703 & $1.241-5.885$ & 0.020 \\
\hline Postop pneumonia* & $30(0.3)$ & $3(1.2)$ & $27(0.3)$ & 4.040 & $1.218-13.047$ & 0.046 \\
\hline Postop bleeding requiring transfusion* & $1057(11.4)$ & $27(10.8)$ & $1030(11.4)$ & 1.066 & $0.711-1.598$ & 0.840 \\
\hline Postop reintubation (unplanned) ${ }^{*}$ & $77(0.8)$ & $4(1.6)$ & $73(0.8)$ & 2.007 & $0.728-5.534$ & 0.151 \\
\hline Preop leukocytosis (age-adjusted) & $240(2.6)$ & $10(4.0)$ & $230(2.5)$ & 1.668 & $0.867-3.206$ & 0.142 \\
\hline Preop leukopenia (age-adjusted) & $572(6.2)$ & $9(3.6)$ & $563(6.2)$ & 0.560 & $0.286-1.096$ & 0.108 \\
\hline
\end{tabular}

Chemo = chemotherapy; CLD = chronic lung disease; CVA = cerebrovascular accident; GI = gastrointestinal; IV = intravenous; $N G$ = nasogastric; $R T$ = radiation therapy; SIRS = systemic inflammatory response syndrome; TBI = traumatic brain injury.

Data are presented as number of cases (\%) unless otherwise indicated. Statistical analysis was performed using the chi-square test or Fisher exact test where appropriate. Boldface type indicates statistical significance $(p<0.05)$. For more specific comorbidity variable definitions, please refer to the NSQIP-P user guides $($ References $3-5)$.

* Postoperative complications that occurred after or concurrent with SSI development were not included in the risk factor analysis.

of each aforementioned procedure could play a role in the likelihood of SSI development. Distribution of SSI rate by procedure category was similar between the NSQIP-P and COA data sets, providing evidence in favor of NSQIP-P validity-at least on an epidemiological and categorical outcomes level.

Both Chiari decompression and craniosynostosis/craniofacial procedure categories were at significantly lower risk of 30-day SSI compared with other procedure cate- gories. The SSI rate reported here for these categories is comparable to previous studies. In their literature review on Chiari malformation Type I, Arnautovic et al. ${ }^{6}$ reported wound infection rates after Chiari decompression surgery ranging from $1 \%$ to $9 \%$ (median 3\%). A retrospective review of SSI after intracranial surgery for craniofacial malformations at a single institution reported an SSI rate of $3.2 \% .^{52}$ The findings in NSQIP-P were consistent with institutional data from COA, with both Chiari decompression 
TABLE 4. Hospital factors and unadjusted univariate 30-day SSI associations

\begin{tabular}{|c|c|c|c|c|c|c|c|c|}
\hline \multirow[b]{2}{*}{ Parameter } & \multicolumn{4}{|c|}{ NSQIP-P } & \multicolumn{4}{|c|}{$\mathrm{COA}$} \\
\hline & Overall & SSI & $\begin{array}{c}\text { OR } \\
(95 \% \mathrm{Cl})\end{array}$ & $\begin{array}{c}\mathrm{p} \\
\text { Value }\end{array}$ & Overall & SSI & $\begin{array}{c}\text { OR } \\
(95 \% \mathrm{Cl})\end{array}$ & $\begin{array}{c}\mathrm{p} \\
\text { Value }\end{array}$ \\
\hline $\begin{array}{l}\text { Length of stay from admission } \\
\text { to discharge in days, mean }\end{array}$ & $5.5 \pm 10.5$ & $10.3 \pm 15.2$ & $1.014^{*}(1.008-1.021)$ & $<0.001$ & $11.1 \pm 25.9$ & $16.9 \pm 34.1$ & $1.005^{*}(0.997-1.013)$ & 0.192 \\
\hline $\begin{array}{l}\text { Time from operation to dis- } \\
\text { charge in days, meant }\end{array}$ & $4.9 \pm 7.2$ & $3.8 \pm 2.5$ & $0.966^{*}(0.932-1.001)$ & 0.057 & $8.3 \pm 22.3$ & $3.5 \pm 4.5$ & $0.938^{*}(0.873-1.009)$ & 0.084 \\
\hline $\begin{array}{l}\text { Time from admission to } \\
\text { operation in days, mean }\end{array}$ & $0.8 \pm 8.1$ & $0.9 \pm 2.7$ & $1.000^{*}(0.986-1.015)$ & 0.954 & $2.9 \pm 13.5$ & $2.4 \pm 4.9$ & $0.995^{*}(0.957-1.035)$ & 0.817 \\
\hline \multicolumn{9}{|l|}{ Patient status } \\
\hline Inpatient & 8658 (93.1) & $241(2.8)$ & Ref & & $1103(100)$ & $36(3.3)$ & & \\
\hline Outpatient & $638(6.9)$ & $10(1.6)$ & $0.556(0.294-1.052)$ & 0.075 & $0(0)$ & $0(0)$ & NA & \\
\hline \multicolumn{9}{|l|}{ Admission source } \\
\hline Home/doctor's office/clinic & $8046(86.2)$ & $199(2.5)$ & Ref & & - & - & - & - \\
\hline ER & 766 (8.2) & $30(3.9)$ & $1.607(1.087-2.377)$ & 0.017 & - & - & - & - \\
\hline Outside hospital/rehab & $388(4.2)$ & $15(3.9)$ & $1.586(0.929-2.707)$ & 0.091 & - & - & - & - \\
\hline Other & $96(1.0)$ & $7(7.3)$ & $3.101(1.419-6.780)$ & 0.005 & - & - & - & - \\
\hline Discharge destination & & & & & - & - & - & - \\
\hline Home & $8856(95.3)$ & $231(2.6)$ & Ref & & - & - & - & - \\
\hline Other & $440(4.7)$ & $20(4.5)$ & $1.778(1.114-2.837)$ & 0.022 & - & - & - & - \\
\hline Prior operation w/in 30 days & $104(1.1)$ & $2(1.9)$ & $0.704(0.173-2.870)$ & 1.000 & $205(18.6)$ & $5(2.4)$ & $0.699(0.269-1.821)$ & 0.662 \\
\hline Concurrent procedure & $675(7.3)$ & $21(3.1)$ & $1.171(0.744-1.844)$ & 0.460 & - & - & - & - \\
\hline
\end{tabular}

ER = emergency room; rehab = rehabilitation facility.

Data are presented as number of cases (\%) unless otherwise indicated. Continuous variables are expressed as mean \pm SD. Statistical tests were performed using the

Student t-test, chi-square test, and Fisher exact test where appropriate. Boldface type indicates statistical significance $(p<0.05)$.

* Per day increase.

$†$ Cases in which discharge occurred after or concurrent with SSI diagnosis were excluded from the statistical risk analysis.

and craniosynostosis/craniofacial being among the procedure categories with the lowest SSI rates in both data sets.

Myelomeningocele procedures approached but did not reach statistical significance as an independent risk factor for SSI. This may be partially due to the relatively low number of MMC closure procedures performed, which may decrease power and increase likelihood of a Type II (i.e., false negative) statistical error. The SSI rate reported here $(4.4 \%)$ is relatively low compared with previous studies. One study of 91 MMC procedures found a meningitis/ shunt infection rate of $16.4 \%$ and a surgical wound infection rate of $11.0 \% .^{14}$

\section{Independent Risk Factors}

Independent risk factors for SSI were identified in both data sets. Importantly, risk factors were not very similar between data sets. The discrepancy in variables collected by the 2 data sets is the most likely explanation for discrepant risk factors. Of note, the COA database did not track any preexisting patient comorbidities-neurological or nonneurological-whereas NSQIP contains predefined comorbidities, several of which were SSI risk factors. Additionally, the NSQIP database did not track certain intraoperative or administrative variables (e.g., number of personnel in operating room, use of an implant, insurance status) that were tracked in the COA data set. Other than female sex as an SSI risk factor in the NSQIP results, the remainder of the SSI risk factors are relatively unsurpris- ing in both data sets. The similar time to SSI and similar rates of overall SSI/procedural SSI between data sets supports the notion of data set similarity, yet the risk factor discrepancy may simply reflect differences in risk factor variables collected per data set. Despite these discrepancies, the results of the multivariate analysis met acceptable levels of predictive accuracy for the NSQIP-P analysis (ROC curve AUC or C-statistic 0.713) and yielded several significant findings.

Postoperative pneumonia (in the absence of preceding SSI) was an independent risk factor for SSI. However, one limitation of this finding is that pneumonia may precede later SSI and can therefore be thought of as a "risk factor" per se, but the actual clinical significance of this relationship is unclear. Additionally, patients with a higher degree of medical complexity or with comorbid medical conditions may be predisposed to pneumonia in the same way they are predisposed to SSI. Only 3 patients had postoperative pneumonia preceding SSI, increasing the likelihood of a false-positive statistical test result (Type I error). Therefore, this finding should be interpreted with caution.

One of the strongest categorical risk factors for SSI was immune disease or immunosuppressant use. This finding has been demonstrated as a risk factor for SSI in previous literature. ${ }^{31}$ Intuitively, it also follows that immune suppression or deficiency will likely predispose patients to infection. Implementation of SSI prophylaxis measures (e.g., preoperative antibiotics, antibiotic sutures, intraoperative 
TABLE 5. Operative factors and unadjusted univariate 30-day SSI association

\begin{tabular}{|c|c|c|c|c|c|c|c|c|}
\hline \multirow[b]{2}{*}{ Parameter } & \multicolumn{4}{|c|}{ NSQIP-P } & \multicolumn{4}{|c|}{$\mathrm{COA}$} \\
\hline & Overall & SSI & $\begin{array}{c}\text { OR } \\
(95 \% \mathrm{Cl})\end{array}$ & $\begin{array}{c}\mathrm{p} \\
\text { Value }\end{array}$ & Overall & SSI & $\begin{array}{c}\mathrm{OR} \\
(95 \% \mathrm{Cl})\end{array}$ & $\begin{array}{c}p \\
\text { Value }\end{array}$ \\
\hline $\begin{array}{l}\text { Length of operation } \\
\text { in mins, mean }\end{array}$ & $165.8 \pm 119.3$ & $198.0 \pm 150.7$ & $1.120^{*}(1.064-1.179)$ & $<0.001$ & $159.8 \pm 116.5$ & $191.1 \pm 128.6$ & $1.136^{*}(0.974-1.326)$ & 0.104 \\
\hline $\begin{array}{l}\text { Duration of anesthe- } \\
\text { sia in mins, mean }\end{array}$ & $259.0 \pm 142.7$ & $294.6 \pm 172.4$ & $1.096^{*}(1.048-1.146)$ & $<0.001$ & - & - & - & - \\
\hline $\begin{array}{l}\text { Length of time from } \\
\text { anesthesia start to } \\
\text { operation start in } \\
\text { mins, mean }\end{array}$ & $67.6 \pm 40.4$ & $68.5 \pm 30.8$ & $1.032^{*}(0.878-1.214)$ & 0.702 & - & - & - & - \\
\hline $\begin{array}{l}\text { Length of time from } \\
\text { operation stop to } \\
\text { anesthesia stop in } \\
\text { mins, mean }\end{array}$ & $26.3 \pm 20.8$ & $28.2 \pm 17.8$ & $1.217^{*}(0.934-1.586)$ & 0.144 & - & - & - & - \\
\hline \multicolumn{9}{|l|}{ Operation status } \\
\hline Elective & 8489 (91.3) & $219(2.6)$ & Ref & & - & - & - & - \\
\hline Emergency & $350(3.8)$ & $19(5.4)$ & $2.168(1.339-3.508)$ & 0.002 & - & - & - & - \\
\hline Urgent & $457(4.9)$ & $13(2.8)$ & $1.106(0.627-1.950)$ & 0.729 & - & - & - & - \\
\hline \multicolumn{9}{|l|}{ ASA class } \\
\hline Class I & $733(7.9)$ & $11(1.5)$ & Ref & & - & - & - & - \\
\hline Class II & $4102(44.1)$ & $99(2.4)$ & $1.623(0.866-3.042)$ & 0.131 & - & - & - & - \\
\hline Class III & $4171(44.9)$ & $131(3.4)$ & $2.128(1.145-3.958)$ & 0.017 & - & - & - & - \\
\hline Class IV & $262(2.8)$ & $8(3.1)$ & $2.067(0.822-5.197)$ & 0.123 & - & - & - & - \\
\hline Class V & $5(0.1)$ & $0(0.0)$ & NA & & - & - & - & - \\
\hline Unknown & $23(0.2)$ & $2(8.7)$ & $6.251(1.303-29.983)$ & 0.022 & - & - & - & - \\
\hline $\begin{array}{l}\text { Periop blood transfu- } \\
\text { sion }\end{array}$ & $1057(11.4)$ & $27(2.6)$ & $1.066(0.711-1.598)$ & 0.840 & $179(16.2)$ & $3(1.7)$ & $0.460(0.140-1.517)$ & 0.252 \\
\hline \multicolumn{9}{|l|}{ Wound classification } \\
\hline Clean & $8997(96.8)$ & $248(2.8)$ & Ref & & $986(92.0)$ & $30(3.0)$ & Ref & \\
\hline $\begin{array}{l}\text { Clean-contami- } \\
\text { nated }\end{array}$ & $188(2.0)$ & $1(0.5)$ & $0.189(0.026-1.352)$ & 0.097 & $57(5.3)$ & $5(8.8)$ & 3.064 (1.142-8.222) & 0.026 \\
\hline Contaminated & $74(0.8)$ & $2(2.7)$ & $0.980(0.239-4.017)$ & 0.978 & $22(2.1)$ & $1(4.5)$ & $1.517(0.198-11.655)$ & 0.688 \\
\hline Dirty/infected & $37(0.4)$ & $0(0)$ & NA & & $7(0.7)$ & $0(0)$ & & \\
\hline $\begin{array}{l}\text { No. of personnel in } \\
\text { operating room, } \\
\text { mean }\end{array}$ & - & - & - & - & $12.6 \pm 3.2$ & $13.4 \pm 2.5$ & $1.083(0.981-1.195)$ & 0.113 \\
\hline Implant used & - & - & - & - & $579(52.5)$ & $19(3.3)$ & $1.012(0.520-1.968)$ & $>0.99$ \\
\hline $\begin{array}{l}\text { Multiple circulator } \\
\text { nurses }\end{array}$ & - & - & - & - & 784 (71.1) & $31(4.0)$ & $2.585(0.996-6.710)$ & 0.059 \\
\hline Multiple scrub nurses & - & - & - & - & $631(57.2)$ & $22(3.5)$ & $1.182(0.598-2.335)$ & 0.733 \\
\hline $\begin{array}{l}\text { Prophylactic antibiot- } \\
\text { ics used }\end{array}$ & - & - & - & - & 1016 (92.1) & $34(3.3)$ & $1.471(0.348-6.231)$ & 0.598 \\
\hline \multicolumn{9}{|l|}{ Quarter of operation } \\
\hline Q1 & - & - & - & - & $342(31.0)$ & $11(3.2)$ & Ref & \\
\hline Q2 & - & - & - & - & $287(26.0)$ & $9(3.1)$ & $0.974(0.398-2.385)$ & 0.974 \\
\hline Q3 & - & - & - & - & $231(20.9)$ & $8(3.5)$ & $1.079(0.427-2.726)$ & 0.871 \\
\hline Q4 & - & - & - & - & $243(22.0)$ & $8(3.3)$ & $1.024(0.406-2.586)$ & 0.959 \\
\hline
\end{tabular}

ASA = American Society of Anesthesiologists; Q1 = first quarter; $Q 2$ = second quarter; $\mathrm{Q} 3$ = third quarter; $\mathrm{Q} 4$ = fourth quarter.

Data are presented as number of cases (\%) unless otherwise indicated. Statistical tests were performed using the Student t-test, chi-square test, and Fisher exact test where appropriate. Boldface type indicates statistical significance $(p<0.05)$.

* Per hour increase.

$\dagger$ Based on total number of personnel present. 
TABLE 6. Variables independently associated with 30-day SSI via multivariate binary logistic regression

\begin{tabular}{|c|c|c|c|}
\hline Variable & $\begin{array}{c}\text { Adjusted } \\
\text { OR }\end{array}$ & $95 \% \mathrm{Cl}$ & $\begin{array}{c}p \\
\text { Value }\end{array}$ \\
\hline \multicolumn{4}{|l|}{ NSQIP-P parameters } \\
\hline Postop pneumonia* & 4.761 & $1.269-17.857$ & 0.021 \\
\hline $\begin{array}{l}\text { Immune disease or immunosup- } \\
\text { pressant use }\end{array}$ & 3.671 & $1.371-9.827$ & 0.010 \\
\hline Cerebral palsy & 2.835 & $1.463-5.494$ & 0.002 \\
\hline Emergency operation & 1.843 & $1.011-3.360$ & 0.046 \\
\hline Spine procedure & 1.673 & $1.036-2.702$ & 0.035 \\
\hline Acquired CNS abnormality & 1.620 & $1.085-2.420$ & 0.018 \\
\hline Female sex & 1.475 & $1.062-2.049$ & 0.021 \\
\hline \multicolumn{4}{|l|}{ COA parameters } \\
\hline Clean-contaminated wound class & 3.887 & $1.354-11.153$ & 0.012 \\
\hline Public insurance & 1.966 & $0.957-4.041$ & 0.066 \\
\hline Spine procedure & 1.982 & $0.955-4.114$ & 0.066 \\
\hline
\end{tabular}

antibiotic powder) and careful postoperative wound care in immunosuppressed patients may help protect against SSI in these patients. NSQIP-P does not include specific information regarding type of immunodeficiency, immunosuppressant medications, etc., which is a limitation of this finding.

The only procedural category that emerged as an independent risk factor in NSQIP-P was spine. The spine procedure category approached significance in the COA results $(p=0.066)$. These results may indicate room for quality improvement in spine surgery, especially with respect to laminectomies (which had particularly high SSI rates). Previous studies on SSI in pediatric spinal deformity surgery have reported SSI rates of 5.5\% ${ }^{28}$ The relative lack of vascularity in paraspinal tissue, especially relative to pericranial vascularity, may predispose to infection. Studies in adults support this claim, as spinal SSI rates are higher than cranial SSI rates in very large patient populations. ${ }^{13,25}$

Patients who underwent emergency surgeries were at significantly greater risk of SSI development. There are many potential explanations for this observation, including more severe underlying disease and more complex and longer operations (shown to be significant on univariate analysis itself). Furthermore, appropriate preventative measures for SSI prophylaxis may be more difficult to implement in emergency cases.

Cerebral palsy was noted to be an independent risk factor in the NSQIP-P data. Cerebral palsy may be indicative of more debilitating underlying conditions that might predispose to SSI, such as neuromuscular scoliosis. ${ }^{28}$ Acquired CNS abnormality was found to be an independent risk factor as well. Acquired CNS abnormalities are most likely related to injury or infection that may predispose to SSI by a similar mechanism as developmental delay. However, available data regarding acquired CNS abnormality are insufficiently granular to make inferences about links between particular patient conditions and SSI risk.
Perhaps the most surprising finding of the NSQIP$\mathrm{P}$ analysis was that female sex was an independent risk factor for SSI, with female patients having approximately $40 \%$ greater odds of SSI than male patients on adjusted analysis. The odds ratio for female sex showed small effect size (95\% CI 1.062-2.049) and was the smallest of the odds ratios for independently significant risk factors. The results from the COA institutional analysis showed no significant differences between male and female sex. However, there was a trend toward a higher rate of SSI in the COA cohort (3.4\% SSI vs 3.1\% SSI in males). Results from the literature are mixed regarding sex and SSI risk. In pediatric neurosurgery, female sex has been reported as a risk factor for shunt infection (adjusted OR 1.2). ${ }^{44}$ Sex was not a significant predictor of SSI in a study of pediatric spine surgeries. ${ }^{28}$ In adult neurosurgery, female sex has been associated with increased risk of SSI after craniotomy/craniectomy (OR 3.49). ${ }^{12}$ However, an analysis of the adult NSQIP database found that female sex was significantly protective (OR 0.697) against SSI after craniotomy. ${ }^{27}$ In a systematic review of risk factors for adult SSI, exploring results from 57 studies of various surgical procedures, 5 studies found female sex to be an SSI risk factor whereas 4 studies found female sex to be protective. ${ }^{19}$ This finding warrants caution in interpretation of overall results as well. ${ }^{10}$ One potential explanation for this finding may involve the fact that the NSQIP-P data set is reportedly collected via a random case sample on a weekly cycle. However, achieving a truly random sample is unlikely, and the sample for neurosurgical patients may have contained more female patients who happened to develop SSI. For instance, it could be that the NSQIP sample of the procedures with greatest SSI risk (e.g., MMCs, spine, epilepsy cases) contained more female patients. Ultimately, we are unable to account for the sex differences observed in the present study, and we recommend that future studies specifically examine the relationship between sex and pediatric neurosurgical SSI.

\section{Time to SSI}

The timing to SSI events was similar for NSQIP-P and COA data, with a mean time to SSI of approximately 2 weeks. However, mean time to SSI when considering 90day SSI in the COA data set increased to approximately 3 weeks, yet the data distribution became skewed after accounting for 90-day SSI rates (skewness statistic of 2.035 for 90-day time to infection data vs skewness statistic of -0.073 for 30 -day time to infection data; a greater absolute value of the skewness statistic indicates greater deviation from normal distribution). These data have implications for appropriate timing of postoperative wound checks. Most 30-day SSIs occurred from 1 to 3 weeks postoperatively in both data sets; this is likely the ideal window for postoperative wound checks.

\section{Pertinent Negative Findings}

Numerous variables in this study showed noteworthy lack of association with SSI. Although previous studies have shown that longer operative time is a risk factor for $\mathrm{SSI}^{2,49}$ we did not find longer operative time to be a significant risk factor for SSI on multivariate analysis. We 
analyzed operative time as a continuous variable rather than as an interval variable, and our method may be less likely to show a statistically significant result for substantially longer operations. Wound classification in NSQIP-P showed no difference in risk for SSI on multivariate analysis despite the intuitive assumption that wound classification stratifies risk for SSI. However, the clean-contaminated wound class was independently predictive of SSI in the COA data. Interestingly, several other large NSQIP-P studies have found that wound classification is not a significant predictor of SSI..$^{29,30}$ There may be substantial interrater or interhospital variation in wound classification, decreasing the utility of this variable as a predictor of infection.

Blood transfusion has been shown to be a risk factor for SSI, ${ }^{46}$ although no differences were seen here. Premature patients were not at increased SSI risk despite previous studies showing otherwise. ${ }^{23}$ However, in studies showing prematurity to be a risk factor for SSI, it is difficult to determine if prematurity alone is responsible for increased SSI risk. Preoperative sepsis did not increase risk for postoperative SSI, likely because SSI is typically caused by foreign/external infection rather than internal. Steroid use has been shown to increase risk for SSI in adult neurosurgical populations but was not significant on multivariate analysis in this study. ${ }^{24,25}$ This is an interesting negative finding given that immune disease/immunosuppressant use was found to be a significant and independent risk factor, whereas steroid use was not independently significant (although steroid use approached significance via univariate analysis). The lack of SSI association with steroid use yet significant SSI association with immune disease/immunosuppressant use may indicate that immune disease is a stronger predictor of SSI than immunosuppressant medication alone. However, the discordant findings may indicate variability in the NSQIP-P data.

In the COA data, variables that were not included in NSQIP-P, such as prophylactic antibiotic use, implant use, and presence of multiple scrub nurses, were not associated with SSI risk. These findings, coupled with the ROC accuracy analysis, may indicate that NSQIP-P is sufficient for analysis of postoperative SSI. Many of the criticisms of NSQIP-P stem from its lack of neurosurgery-specific data and variables like medication use during/before surgery; however, these types of variables did not appear to make a noticeable difference in SSI outcome. Importantly, given the independent significance of public insurance as a risk factor in the COA data, the lack of socioeconomic variables in NSQIP-P rather than surgery-specific variables may be a more important deficiency.

\section{SSI Prevention}

Due to SSI-associated morbidity, cost of care, and return to system, SSI prevention has been and should continue to be a major objective of all surgeons. Surgical site infection is a major risk factor for unplanned readmission following pediatric neurosurgery, leading to increased cost and resource allocation. ${ }^{42}$ Within pediatric neurosurgery, numerous studies have described various methods of SSI prevention, mostly within the scope of preventing shunt infection. Implementation of infection prevention protocols has significantly decreased rates of infection in shunt and spine surgery, ${ }^{16,17,36,40,41}$ demonstrating room for quality improvement and potential application of similar protocols in general neurosurgical nonshunt surgery. While previous studies have demonstrated reduced SSI rates with interventions such as antibiotic-impregnated sutures, ${ }^{40}$ double gloving, ${ }^{47}$ administration of intraoperative bacitracin or vancomycin powder prior to wound closure, ${ }^{1,8,9}$ and appropriately dosing antibiotics and minimizing hypothermia, ${ }^{15}$ none of these factors were significantly associated with SSI in either the NSQIP-P or institutional analysis. In fact, no modifiable risk factors were identified in either analysis.

\section{Study Limitations}

One limitation of this study is the lack of follow-up for SSI and SSI-associated complications beyond 30 days after surgery. Previous studies and the authors' review of COA institutional data have conclusively demonstrated that SSI in pediatric neurosurgery certainly can occur well after 30 days postoperatively. ${ }^{39}$ The results of this study, particularly regarding rates of SSI with a longer time horizon, should therefore be interpreted with caution as underreporting is a concern. Nevertheless, our institutional data showed little absolute increase in infections when the follow-up period was extended to 90 days instead of only 30 days (3.9\% vs $3.3 \%$ ). While the increase shows that the risk of infection exists beyond 30 days, the small size of the increase supports the notion that the 30-day infection rate is a reasonable indicator of overall infection rate.

NSQIP-P and COA definitions of SSI differ. In particular, SSI in the COA database requires positive cultures (of wound, blood, CSF, abscess, etc.), and time to SSI in COA was determined by time to culture collection. However, SSI in NSQIP requires that only one of several criteria be positive, with the time to SSI coded as time to the first positive required criterion. Therefore, the risk for underreporting noncultured, yet clinically significant, SSI is higher in the COA data, especially for superficial infections. Furthermore, time to SSI was captured differently between the NSQIP-P and COA data sets.

The NSQIP-P database lacks neurosurgery-specific and SSI-specific variables of importance, such as antibioticimpregnated catheter use, number of personnel in operating room, causative organism(s), method of SSI determination/diagnosis, incision size, specific type of organ/space SSI (e.g., meningitis vs ventriculitis), laboratory results, culture site/results, and prophylactic antibiotic use. These limitations of the NSQIP-P data set have received previous attention in the pediatric neurosurgical literature. ${ }^{10}$ While inclusion of SSI-specific and neurosurgery-specific variables in NSQIP-P may help better predict SSI, our institutional data did not show any significant difference in SSI rates even after accounting for these variables. In a recent editorial, Lam et al. discuss limitations of patient databases and point out the "need to examine codes in detail and aspire to validate them with institutional clinical data in the study process." 22 We feel that our current study adds value by providing such a comparison.

The relative frequency of different procedure types in our analysis may be skewed due to epilepsy procedures not being present in the 2012 and 2013 data sets. The seemingly low volume of cases in the NSQIP-P data relative to 
the COA case volume is due to the random sampling cycle from NSQIP-P. NSQIP-P does not include all of the surgical cases from participating institutions due to concern for overworking data abstractors. Instead, they implement an 8-day cycle of random case sampling. ${ }^{3-5}$ Therefore, it is expected that the NSQIP-P national data will not contain a proportionally greater number of cases relative to $\mathrm{COA}$ volume. The lower number of epilepsy procedures could result in Type II (false negative) statistical error due to underpowered sampling.

NSQIP-P does not include trauma cases, which presumably excludes a substantial and relevant portion of neurosurgery cases such as hematoma evacuation. However, COA data showed no association of hematoma evacuation with SSI risk in a preliminary subgroup analysis (not presented here). Thus the lack of these data in NSQIP-P may not be a substantial shortcoming.

NSQIP-P also lacks data on time of year in which the operation occurred, which may yield important information regarding seasonal risk for SSI. However, the COA analysis showed no difference in SSI rates by calendar quarter of operation.

Finally, there is risk of Type I (false positive) statistical error due to the large number of independent variables analyzed relative to the number of dependent variable outcomes in NSQIP-P. However, the creation of a multivariate model by selecting variables based on the results of univariate analyses inherently corrects for the problem of multiple measures to some degree. Some variables, such as postoperative pneumonia, had very few occurrences and therefore may lead to spurious statistical test results.

Regarding limitations of the COA data, the COA data set lacks patient comorbidity information, which may help explain the difference in ROC curve analysis between NSQIP-P and COA even though the COA data set contains more neurosurgery-specific operative data. The COA data reflect the experience at a single institution and represent an imperfect metric with which to compare NSQIP-P data. Data were analyzed from the 2009 through 2012 period primarily to avoid duplicating cases between NSQIP-P and COA for comparison; however, these data are relatively old and the clinical utility of such data may be limited. Finally, Type II statistical error is possible in the COA data set analysis due to the relatively low number $(n=36)$ of SSI outcomes and procedures for certain categories (e.g., Chiari decompression and craniosynostosis/craniofacial procedures).

Despite these limitations, this study may help pediatric neurosurgeons identify risk factors for developing SSI and institute appropriate measures to help prevent SSI where practical and reasonable.

\section{Conclusions}

We have identified rates of and risk factors for 30-day SSI after nonshunt pediatric neurosurgery using a national database and an institutional database. NSQIP-P data and data from a single institution were similar across many aspects. Pediatric patients undergoing spine surgery, craniotomy for epilepsy, and MMC closure procedures are at particularly high risk for SSI. Postoperative pneumonia, immune disease/immunosuppressant use, cerebral palsy, emergency operation, spine procedure category, acquired CNS abnormality, and female sex all independently increased SSI risk in NSQIP-P, whereas clean-contaminated wound classification independently predicted SSI in data from a single center.

Substantially similar SSI rates were identified in both the national NSQIP-P data and our local institutional data. However, the independent risk factors and methods for SSI capture differed in the 2 data sets.

Finally, few of the risk factors identified here are modifiable. Nevertheless, at-risk populations may benefit from more directed efforts at reducing surgical site infection.

\section{Acknowledgments}

We wish to acknowledge Steven Veselsky, Kyle Aune, Rachel Crutchfield, Chao Ju, Chelsea Lynch, and Delaney Garner for their efforts in maintaining the Children's of Alabama institutional infection database.

Dr. Rocque is supported by NIH Grant 1KL2TR001419 and by the Kaul Pediatric Research Institute of Children's of Alabama.

The ACS NSQIP and the hospitals participating in the ACS NSQIP-P are the source of the data used herein; they have not verified and are not responsible for the statistical validity of the data analysis or the conclusions derived by the authors.

\section{References}

1. Abdullah KG, Attiah MA, Olsen AS, Richardson A, Lucas TH: Reducing surgical site infections following craniotomy: examination of the use of topical vancomycin. J Neurosurg 123:1600-1604, 2015

2. Abu Hamdeh S, Lytsy B, Ronne-Engström E: Surgical site infections in standard neurosurgery procedures- a study of incidence, impact and potential risk factors. Br J Neurosurg 28:270-275, 2014

3. American College of Surgeons: User Guide for the $\mathbf{2 0 1 2}$ ACS NSQIP Pediatric Participant Use Data File. Chicago: American College of Surgeons, 2013 (https://www.facs.org/ / media/files/quality\%20programs/nsqip/2012pedsuserguide. ashx) [Accessed December 15, 2016]

4. American College of Surgeons: User Guide for the 2013 ACS NSQIP Pediatric Participant Use Data File. Chicago: American College of Surgeons, 2014 (https://www.facs. org/ /media/files/quality\%20programs/nsqip/peds_puf_ userguide_2013.ashx) [Accessed December 15, 2016]

5. American College of Surgeons: User Guide for the 2014 ACS NSQIP Pediatric Participant Use Data File. Chicago: American College of Surgeons, 2015 (https://www.facs.org/ / media/files/quality\%20programs/nsqip/peds_acs_nsqip_puf_ userguide_2014.ashx) [Accessed December 15, 2016]

6. Arnautovic A, Splavski B, Boop FA, Arnautovic KI: Pediatric and adult Chiari malformation Type I surgical series 1965-2013: a review of demographics, operative treatment, and outcomes. J Neurosurg Pediatr 15:161-177, 2015

7. Attenello FJ, Garces-Ambrossi GL, Zaidi HA, Sciubba DM, Jallo GI: Hospital costs associated with shunt infections in patients receiving antibiotic-impregnated shunt catheters versus standard shunt catheters. Neurosurgery 66:284-289, 2010

8. Beckman JM, Amankwah EK, Tetreault LL, Perlman SA, Tuite GF: Complications associated with bacitracin powder in surgical wounds. J Neurosurg Pediatr 16:719-725, 2015

9. Beckman JM, Amankwah EK, Tetreault LL, Tuite GF: Reduction in CSF shunt infection over a 10-year period associated with the application of concentrated topical antibiotic powder directly to surgical wounds prior to closure. J Neurosurg Pediatr 16:648-661, 2015 
10. Brockmeyer D: Editorial. Does it pass the sniff test? Mining the NSQIP-P database for neurosurgical diseases. J Neurosurg Pediatr 18:413-415, 2016

11. Bruny JL, Hall BL, Barnhart DC, Billmire DF, Dias MS, Dillon PW, et al: American College of Surgeons National Surgical Quality Improvement Program Pediatric: a beta phase report. J Pediatr Surg 48:74-80, 2013

12. Chiang HY, Steelman VM, Pottinger JM, Schlueter AJ, Diekema DJ, Greenlee JD, et al: Clinical significance of positive cranial bone flap cultures and associated risk of surgical site infection after craniotomies or craniectomies. J Neurosurg 114:1746-1754, 2011

13. Dashti SR, Baharvahdat H, Spetzler RF, Sauvageau E, Chang SW, Stiefel MF, et al: Operative intracranial infection following craniotomy. Neurosurg Focus 24(6):E10, 2008

14. Demir N, Peker E, Gülşen İ, A ğengin K, Tuncer O: Factors affecting infection development after meningomyelocele repair in newborns and the efficacy of antibiotic prophylaxis. Childs Nerv Syst 31:1355-1359, 2015

15. Elward A, Yegge J, Recktenwald A, Jadwisiak L, Kieffer P, Hohrein M, et al: Risk factors for craniotomy or spinal fusion surgical site infection. Pediatr Infect Dis J 34:1323-1328, 2015

16. Kestle JR, Holubkov R, Douglas Cochrane D, Kulkarni AV, Limbrick DD Jr, Luerssen TG, et al: A new Hydrocephalus Clinical Research Network protocol to reduce cerebrospinal fluid shunt infection. J Neurosurg Pediatr 17:391-396, 2016

17. Kestle JR, Riva-Cambrin J, Wellons JC III, Kulkarni AV, Whitehead WE, Walker ML, et al: A standardized protocol to reduce cerebrospinal fluid shunt infection: the Hydrocephalus Clinical Research Network Quality Improvement Initiative. J Neurosurg Pediatr 8:22-29, 2011

18. Kirkland KB, Briggs JP, Trivette SL, Wilkinson WE, Sexton DJ: The impact of surgical-site infections in the 1990s: attributable mortality, excess length of hospitalization, and extra costs. Infect Control Hosp Epidemiol 20:725-730, 1999

19. Korol E, Johnston K, Waser N, Sifakis F, Jafri HS, Lo M, et al: A systematic review of risk factors associated with surgical site infections among surgical patients. PLoS One 8:e83743, 2013

20. Kulaylat AN, Engbrecht BW, Rocourt DV, Rinaldi JM, Santos MC, Cilley RE, et al: Measuring surgical site infections in children: comparing clinical, electronic, and administrative data. J Am Coll Surg 222:823-830, 2016

21. Kulkarni AV, Drake JM, Lamberti-Pasculli M: Cerebrospinal fluid shunt infection: a prospective study of risk factors. J Neurosurg 94:195-201, 2001

22. Lam S, Pan IW, Jea A, Luerssen TG: Bridging the gap between administrative data and clinical observations. J Neurosurg Pediatr 17:763-764, 2016 (Letter)

23. Lejus C, Dumont R, Gall CL, Guillaud C, Guen CG, Leclair $\mathrm{MD}$, et al: A preoperative stay in an intensive care unit is associated with an increased risk of surgical site infection in neonates. J Pediatr Surg 48:1503-1508, 2013

24. Lieber BA, Appelboom G, Taylor BE, Lowy FD, Bruce EM, Sonabend AM, et al: Preoperative chemotherapy and corticosteroids: independent predictors of cranial surgical-site infections. J Neurosurg 125:187-195, 2016

25. Lieber B, Han B, Strom RG, Mullin J, Frempong-Boadu AK, Agarwal N, et al: Preoperative predictors of spinal infection within the National Surgical Quality Inpatient Database. World Neurosurg 89:517-524, 2016

26. Mangram AJ, Horan TC, Pearson ML, Silver LC, Jarvis WR Guideline for prevention of surgical site infection, 1999. Am J Infect Control 27:96-134, 1999

27. McCutcheon BA, Ubl DS, Babu M, Maloney P, Murphy M, Kerezoudis P, et al: Predictors of surgical site infection following craniotomy for intracranial neoplasms: an analysis of prospectively collected data in the American College of
Surgeons National Surgical Quality Improvement Program database. World Neurosurg 88:350-358, 2016

28. Meng F, Cao J, Meng X: Risk factors for surgical site infection following pediatric spinal deformity surgery: a systematic review and meta-analysis. Childs Nerv Syst 31:521-527, 2015

29. Mioton LM, Jordan SW, Hanwright PJ, Bilimoria KY, Kim JY: The relationship between preoperative wound classification and postoperative infection: a multi-institutional analysis of 15,289 patients. Arch Plast Surg 40:522-529, 2013

30. Ortega G, Rhee DS, Papandria DJ, Yang J, Ibrahim AM, Shore AD, et al: An evaluation of surgical site infections by wound classification system using the ACS-NSQIP. J Surg Res 174:33-38, 2012

31. Ott E, Bange FC, Sohr D, Teebken O, Mattner F: Risk factors associated with surgical site infections following vascular surgery at a German university hospital. Epidemiol Infect 141:1207-1213, 2013

32. Owens CD, Stoessel K: Surgical site infections: epidemiology, microbiology and prevention. J Hosp Infect 70 (Suppl 2):3-10, 2008

33. Parker SL, Attenello FJ, Sciubba DM, Garces-Ambrossi GL, Ahn E, Weingart J, et al: Comparison of shunt infection incidence in high-risk subgroups receiving antibioticimpregnated versus standard shunts. Childs Nerv Syst 25:77-85, 2009

34. Parker SL, Anderson WN, Lilienfeld S, Megerian JT, McGirt MJ: Cerebrospinal shunt infection in patients receiving antibiotic-impregnated versus standard shunts. J Neurosurg Pediatr 8:259-265, 2011

35. Phung J, Mathern GW, Krogstad P: Timing and predictors of fever and infection after craniotomy for epilepsy in children. Pediatr Infect Dis J 32:450-459, 2013

36. Pirotte BJ, Lubansu A, Bruneau M, Loqa C, Van Cutsem N, Brotchi J: Sterile surgical technique for shunt placement reduces the shunt infection rate in children: preliminary analysis of a prospective protocol in 115 consecutive procedures. Childs Nerv Syst 23:1251-1261, 2007

37. Pull ter Gunne AF, Cohen DB: Incidence, prevalence, and analysis of risk factors for surgical site infection following adult spinal surgery. Spine (Phila Pa 1976) 34:1422-1428, 2009

38. Raval MV, Dillon PW, Bruny JL, Ko CY, Hall BL, Moss RL, et al: Pediatric American College of Surgeons National Surgical Quality Improvement Program: feasibility of a novel, prospective assessment of surgical outcomes. J Pediatr Surg 46:115-121, 2011

39. Riva-Cambrin J, Kestle JR, Holubkov R, Butler J, Kulkarni $\mathrm{AV}$, Drake J, et al: Risk factors for shunt malfunction in pediatric hydrocephalus: a multicenter prospective cohort study. J Neurosurg Pediatr 17:382-390, 2016

40. Rozzelle CJ, Leonardo J, Li V: Antimicrobial suture wound closure for cerebrospinal fluid shunt surgery: a prospective, double-blinded, randomized controlled trial. J Neurosurg Pediatr 2:111-117, 2008

41. Ryan SL, Sen A, Staggers K, Luerssen TG, Jea A: A standardized protocol to reduce pediatric spine surgery infection: a quality improvement initiative. J Neurosurg Pediatr 14:259-265, 2014

42. Sherrod BA, Johnston JM, Rocque BG: Risk factors for unplanned readmission within 30 days after pediatric neurosurgery: a nationwide analysis of 9799 procedures from the American College of Surgeons National Surgical Quality Improvement Program. J Neurosurg Pediatr 18:350-362, 2016

43. Simon TD, Hall M, Riva-Cambrin J, Albert JE, Jeffries HE, Lafleur B, et al: Infection rates following initial cerebrospinal fluid shunt placement across pediatric hospitals in the United States. J Neurosurg Pediatr 4:156-165, 2009

44. Simon TD, Butler J, Whitlock KB, Browd SR, Holubkov R, 
Kestle JR, et al: Risk factors for first cerebrospinal fluid shunt infection: findings from a multi-center prospective cohort study. J Pediatr 164:1462-1468, 1468.e1-1468.e2, 2014

45. Sponseller PD, LaPorte DM, Hungerford MW, Eck K, Bridwell KH, Lenke LG: Deep wound infections after neuromuscular scoliosis surgery: a multicenter study of risk factors and treatment outcomes. Spine (Phila Pa 1976) 25:24612466, 2000

46. Talbot TR, D'Agata EM, Brinsko V, Lee B, Speroff T, Schaffner W: Perioperative blood transfusion is predictive of poststernotomy surgical site infection: marker for morbidity or true immunosuppressant? Clin Infect Dis 38:1378-1382, 2004

47. Tulipan N, Cleves MA: Effect of an intraoperative doublegloving strategy on the incidence of cerebrospinal fluid shunt infection. J Neurosurg 104 (1 Suppl):5-8, 2006

48. University of Alabama at Birmingham Institutional Review Board: Frequently asked questions: Is IRB review required for use of public datasets? UAB Research. (http://www.uab. edu/research/administration/offices/IRB/FAQs/Pages/default. aspx?Topic $=$ Datasets) $[$ Accessed December 15, 2016]

49. Valentini LG, Casali C, Chatenoud L, Chiaffarino F, UbertiFoppa C, Broggi G: Surgical site infections after elective neurosurgery: a survey of 1747 patients. Neurosurgery 62:88-96, 2008

50. von Lehe M, Kim HJ, Schramm J, Simon M: A comprehensive analysis of early outcomes and complication rates after 769 craniotomies in pediatric patients. Childs Nerv Syst 29:781-790, 2013

51. Weiss A, Anderson JE, Chang DC: Comparing the National Surgical Quality Improvement Program with the Nationwide Inpatient Sample Database. JAMA Surg 150:815-816, 2015

52. Yeung LC, Cunningham ML, Allpress AL, Gruss JS, Ellenbogen RG, Zerr DM: Surgical site infections after pediatric intracranial surgery for craniofacial malformations: frequency and risk factors. Neurosurgery 56:733-739, 2005

\section{Disclosures}

The authors report no conflict of interest concerning the materials or methods used in this study or the findings specified in this paper.

\section{Supplemental Information Online-Only Content}

Supplemental material is available with the online version of the article.

Supplemental Table S1. https://thejns.org/doi/suppl/10.3171/ 2016.11.PEDS16454.

\section{Previous Presentations}

This paper was presented on December 7, 2016, at the 2016 Annual Meeting of the AANS/CNS Section on Pediatric Neurological Surgery, Orlando, FL.

\section{Author Contributions}

Conception and design: Rocque, Sherrod. Acquisition of data: Sherrod, Arynchyna, Rozzelle. Analysis and interpretation of data: Rocque, Sherrod, Johnston, Rozzelle, Blount, Oakes. Drafting the article: Rocque, Sherrod. Critically revising the article: Rocque, Sherrod, Johnston, Rozzelle, Blount, Oakes. Reviewed submitted version of manuscript: Rocque, Sherrod. Approved the final version of the manuscript on behalf of all authors: Rocque. Statistical analysis: Rocque, Sherrod. Administrative/technical/ material support: Arynchyna. Study supervision: Rocque.

\section{Correspondence}

Brandon G. Rocque, Department of Neurosurgery, Division of Pediatric Neurosurgery, The University of Alabama at Birmingham, 1600 7th Ave. South, Lowder 400, Birmingham, AL 352335294. email: brandon.rocque@childrensal.org. 